\title{
Low Temperature Deformation Induced Microstructure Refinement and Consequent Ultrahigh Toughness of a 20Mn2SiCrNi Bainitic Steel
}

\author{
Yu Tian ${ }^{1}$, Zhunli Tan ${ }^{1, *}$, Ji Li ${ }^{1} \mathbb{D}$, Bo Gao ${ }^{1}$, Min Zhang ${ }^{1}$ and Bingzhe Bai ${ }^{1,2}$ \\ 1 Material Science and Engineering Research Center, School of Mechanical, Electronic and Control Engineering, \\ Beijing Jiaotong University, Beijing 100044, China; 17121354@bjtu.edu.cn (Y.T.); 16121350@bjtu.edu.cn (J.L.); \\ 17116366@bjtu.edu.cn (B.G.); zhangm@bjtu.edu.cn (M.Z.); bzbai@bjtu.edu.cn (B.B.) \\ 2 Key Laboratory of Advanced Materials of Ministry of Education, School of Materials Science and \\ Engineering, Tsinghua University, Beijing 100084, China \\ * Correspondence: 02lzhtan@163.com; Tel.: +86-1381-167-8974
}

Received: 3 November 2019; Accepted: 18 December 2019; Published: 21 December 2019

\begin{abstract}
In this paper, we have studied the influence of deformation on the microstructure and mechanical properties of $20 \mathrm{Mn} 2 \mathrm{SiCrNi}$ bainitic high strength steel processed through a hot rolling route. Simulation of different temperatures and degrees of deformation was carried out via Gleeble-1500. The study suggested that grain size is refined when the deformation is carried out at lower temperature (> Ac3). When the degree of deformation was increased from $20 \%$ to $60 \%$, grain size and microstructure were both refined and the size of retained austenite was reduced. The tensile strength increased from $1345 \mathrm{MPa}$ to $1432 \mathrm{MPa}$. The impact toughness increased from $115 \mathrm{~J} / \mathrm{cm}^{2}$ to $210 \mathrm{~J} / \mathrm{cm}^{2}$ at room temperature, from $63 \mathrm{~J} / \mathrm{cm}^{2}$ to $142 \mathrm{~J} / \mathrm{cm}^{2}$ at $-40{ }^{\circ} \mathrm{C}$. Furthermore, it was observed that the microstructure after air cooling was composed of granular bainite (GB), lath bainite (LB) and martensite/austenite (MA) island for different deformation conditions. The study reveals that the impact toughness of $20 \mathrm{Mn} 2 \mathrm{SiCrNi}$ bainitic high strength steel can be increased by increasing the degree of deformation.
\end{abstract}

Keywords: bainitic steel; deformation; grain refinement; microstructure refinement; toughness

\section{Introduction}

In recent years, with the rapid development of industry, traditional structural steels cannot completely meet development needs. High strength low alloy (HSLA) steels with high toughness and good weldability are widely used in construction machinery, petroleum industry, transportation and other fields [1-3]. High strength and toughness can be obtained by air cooling after fully austenitizing, followed by low temperature tempering of $\mathrm{Mn}-\mathrm{Si}-\mathrm{Cr}$ bainitic low alloy steels [4-8]. In order to meet the needs of a rapidly growing industry, Mn-Si-Cr bainitic low alloy steels with higher tensile strength and ductility simultaneously can be produced by adjusting the composition of steel and processing parameters. As we know, grain refinement is an effective method to improve the toughness of steels while ensuring high strength [9].

There are many ways to refine grain size including alloying, cyclic quenching and thermomechanical controlled process (TMCP). Microalloying, with their precipitation phenomenon in steels, is crucial for the design of alloys in order to achieve the ideal mechanical strength during the TMCP [10,11]. Rational heat treatment such as cyclic quenching used for $1.24 \mathrm{wt} . \%$ carbon steel and hypereutectoid steel reaches more uniformly dispersed finer cementite particles in the austenite matrix [12,13]. Meanwhile, the process has been used for $\mathrm{Mn}-\mathrm{Si}-\mathrm{Cr}$ bainitic low alloy steels [14]. However, alloying with the addition of $\mathrm{Nb}, \mathrm{V}, \mathrm{Ti}$ and other alloying elements increases the cost. The cyclic quenching process, on the other hand, adopts 
rapid heating and cooling in the majority of the situations, which limits its application [15]. As far as high strength steel is concerned, it is generally accepted that TMCP is the preferred approach to refine the grain size and microstructure to enhance mechanical properties [16-18]. A right compression accelerates the formation of deformation induced ferrite for Q690E steel [2]. However, there were a limited number of studies [14] for Mn-Si-Cr bainitic high strength steels, which have a different microstructure and phase transitions, on grain refinement and microstructure refinement by TMCP process. Thus, we explore the effect of degree of deformation during controlled rolling on the mechanical properties of Mn-Si-Cr bainitic high strength steels.

\section{Materials and Methods}

\subsection{Thermal Simulation Experiment}

The chemical composition (wt.\%) of 20Mn2SiCrNi bainitic high strength steel was Fe-0.20C$1.96 \mathrm{Mn}-1.70 \mathrm{Si}-0.65 \mathrm{Cr}-0.60 \mathrm{Ni}$. Steels were melted in a vacuum furnace and forged into $35 \mathrm{~mm}$ thick and $70 \mathrm{~mm}$ wide billets. For the thermal simulation experiment, specimens of dimension, $8 \mathrm{~mm} \times 12 \mathrm{~mm}$, were cut along the length of forged billet by wire cutting. The thermal deformation simulation experiment was carried out in a Gleeble-1500 thermal simulator (Duffers Scientfic, USA) After heating at $10{ }^{\circ} \mathrm{C} / \mathrm{s}$ to $1200{ }^{\circ} \mathrm{C}$ for $5 \mathrm{~min}$, cooling at $1^{\circ} \mathrm{C} / \mathrm{s}$ to $900{ }^{\circ} \mathrm{C}, 950{ }^{\circ} \mathrm{C}, 1000{ }^{\circ} \mathrm{C}$ and $1050{ }^{\circ} \mathrm{C}$, respectively, was applied, while the deformation rate was $0.1 \mathrm{~s}^{-1}, 1 \mathrm{~s}^{-1}$ and $10 \mathrm{~s}^{-1}$. A high temperature extensometer, with the gauge length of $25 \mathrm{~mm}$, was used to measure the deformation during the experiment. After deformation, the sample was cooled to room temperature in water, and stress-strain curves were obtained. The simulated thermal specimens were cut in the middle, polished and etched with supersaturated picric acid solution. The austenite grain size was measured by an optical microscope (OM).

\subsection{Hot Rolling Deformation}

Based on the results of thermal simulation experiments, the conditions of the hot rolling process were conducted with $20 \%$ and $60 \%$ deformation. The hot rolling process is shown in Figure 1 . A forged blank was heated to $1200{ }^{\circ} \mathrm{C}$ for $1 \mathrm{~h}$ and then rolled several times after cooling to $1000{ }^{\circ} \mathrm{C}$. The degree of deformation was controlled to $20 \%$ and $60 \%$, respectively, and the final rolling temperature was controlled at $950{ }^{\circ} \mathrm{C}$. After rolling, the steel was cooled to room temperature in air. Lastly, it was tempered for $2 \mathrm{~h}$ at $280^{\circ} \mathrm{C}$.

Tensile tests were carried out at room temperature using standard specimens with the diameter of $5 \mathrm{~mm}$ by a SUNS 5305 (SUNS, Shenzhen, China) electronic universal testing machine, with an extensometer with the gauge length of $25 \mathrm{~mm}$. JBDS-300B (Kaide, Jinan, China) impact tests machine was used to carry out impact tests at room temperature $\left(25^{\circ} \mathrm{C}\right)$ and low temperature $\left(-40{ }^{\circ} \mathrm{C}\right)$. The specimen was a U-notch impact specimen of dimensions $10 \mathrm{~mm} \times 10 \mathrm{~mm} \times 55 \mathrm{~mm}$ (standard EN10045). The metallographic specimens were cut by wire cutting. After mechanical polishing, specimens were etched with a supersaturated picric acid solution. Original austenite grain size was observed and measured under OM. For scanning electron microscopy (SEM, EVO18, Zeiss, Tokyo, Japan), specimens were etched with $4 \%$ nitric acid alcohol solution. In order to observe the crack growth during impact, the fracture surface was nickel plated, and the side structure was observed along the middle line of the fracture by SEM. Different widths of retained austenite and lath bainite were characterized by transmission electron microscopy (TEM, FEI TECNAI JEM-F200, JEOL, Tokyo, Japan). TEM observation was carried out on thin foils electro-polished by using a solution of $6 \%$ perchloric acid. Morphology and distribution of retained austenite were characterized by electron backscatter diffraction (EBSD, Oxford, London, England). The volume fraction of retained austenite was analyzed by X-ray diffraction (XRD-D/max-2550, Rigaku, Tokyo, Japan) with $\mathrm{Cu} \mathrm{K} \alpha$ radiation at 
room temperature. The integrated intensities of $(200)_{\gamma^{\prime}}(220)_{\gamma^{\prime}}(311)_{\gamma^{\prime}}(200)_{\alpha}$, and $(211)_{\alpha}$ peaks were used to quantify the volume fraction of retained austenite using the following Equations (1), (2) [19]:

$$
\begin{gathered}
V_{\alpha}+V_{\gamma}=1 \\
V_{\gamma}=1.4 I_{\gamma} /\left(I_{\alpha}+1.4 I_{\gamma}\right)
\end{gathered}
$$

where $V_{\alpha}$ and $V_{\gamma}$ are the volume fraction of martensite and retained austenite, respectively. $I_{\alpha}$ and $I_{\gamma}$ are the integrated intensities of $(100)_{\alpha}$ and $(111)_{\gamma}$ peak, respectively.

The carbon content in retained austenite is estimated using Equation (3) [20]:

$$
a_{\gamma}=0.3556+0.00453 x_{C}
$$

where $x_{C}$ is the carbon content in retained austenite and $a_{\gamma}$ is the lattice parameter of retained austenite. The lattice parameters are determined by three austenite peaks position using Cohen's method [5], assuming that $\mathrm{Si}$ and $\mathrm{Mn}$ have little effect on them.

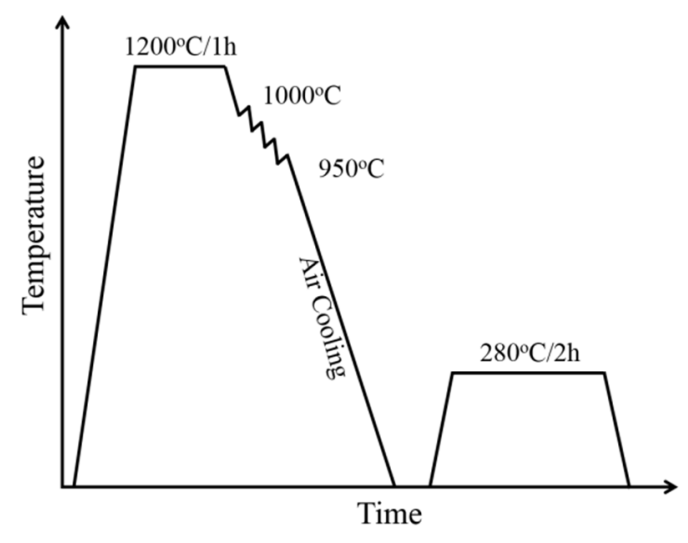

Figure 1. Schematic diagram of hot rolling process.

\section{Results and Discussion}

\subsection{Parameters of Deformation Temperature and Deformation Rate}

The micrographs corresponding to different deformation temperatures are shown in Figure 2. The grain size of the different deformation temperatures $\left(900{ }^{\circ} \mathrm{C}, 950{ }^{\circ} \mathrm{C}, 1000{ }^{\circ} \mathrm{C}, 1050{ }^{\circ} \mathrm{C}\right)$ is $16.8 \pm 2.1 \mu \mathrm{m}, 21.72 \pm 2.5 \mu \mathrm{m}, 24.3 \pm 1.7 \mu \mathrm{m}, 26.2 \pm 0.7 \mu \mathrm{m}$, respectively, as the deformation temperature increases. However, deformation temperature of $900{ }^{\circ} \mathrm{C}$ is in the partial recrystallization zone, and partial recrystallization leads to mixed grain size [21]. Figure 3 shows true stress-true strain curves for different temperatures when the deformation rate is $1 \mathrm{~s}^{-1}$. With the increase of deformation temperature, deformation resistance (peak stress) decreases significantly. When the deformation temperature is $900^{\circ} \mathrm{C}$, the flow stress is $175 \mathrm{MPa}$. Deformation resistance decreases to $152 \mathrm{MPa}$ when deformation temperature increases to $950^{\circ} \mathrm{C}$. It shows that moderately increasing the deformation temperature has an obvious softening effect on the material, which can release the work hardening caused by large plastic deformation and deformation resistance. In actual production, the finishing rolling temperature of the steel is generally $900{ }^{\circ} \mathrm{C}[22,23]$, because lower temperature leads to higher deformation resistance, which necessitates a higher load requirement. Therefore, factors such as grain size and deformation resistance should be taken into account in the selection of the deformation temperature. 

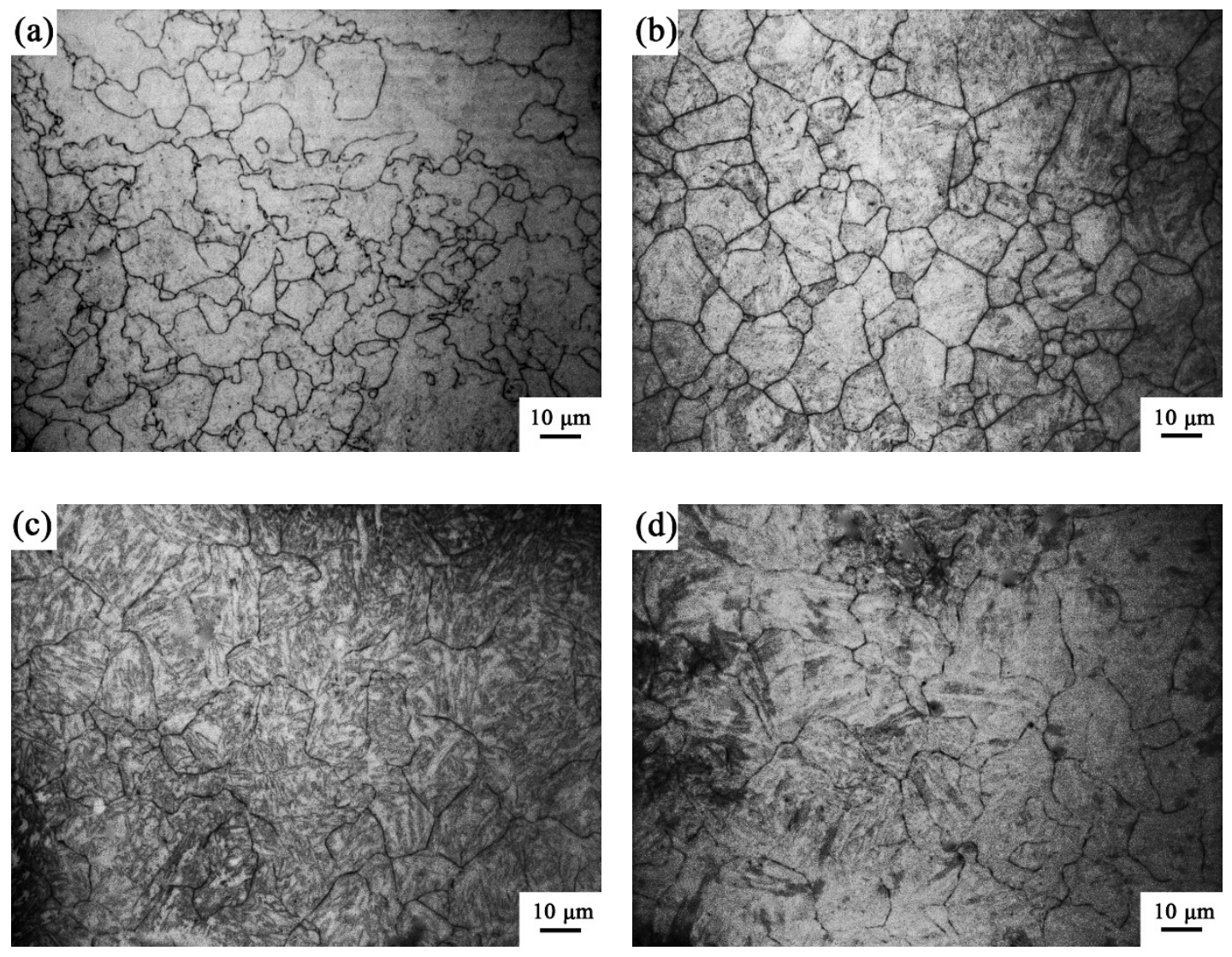

Figure 2. Grain size with deformation temperature (deformation rate: $1 \mathrm{~s}^{-1}$ ): (a) $900{ }^{\circ} \mathrm{C}$; (b) $950{ }^{\circ} \mathrm{C}$; (c) $1000^{\circ} \mathrm{C} ;$ (d) $1050{ }^{\circ} \mathrm{C}$.

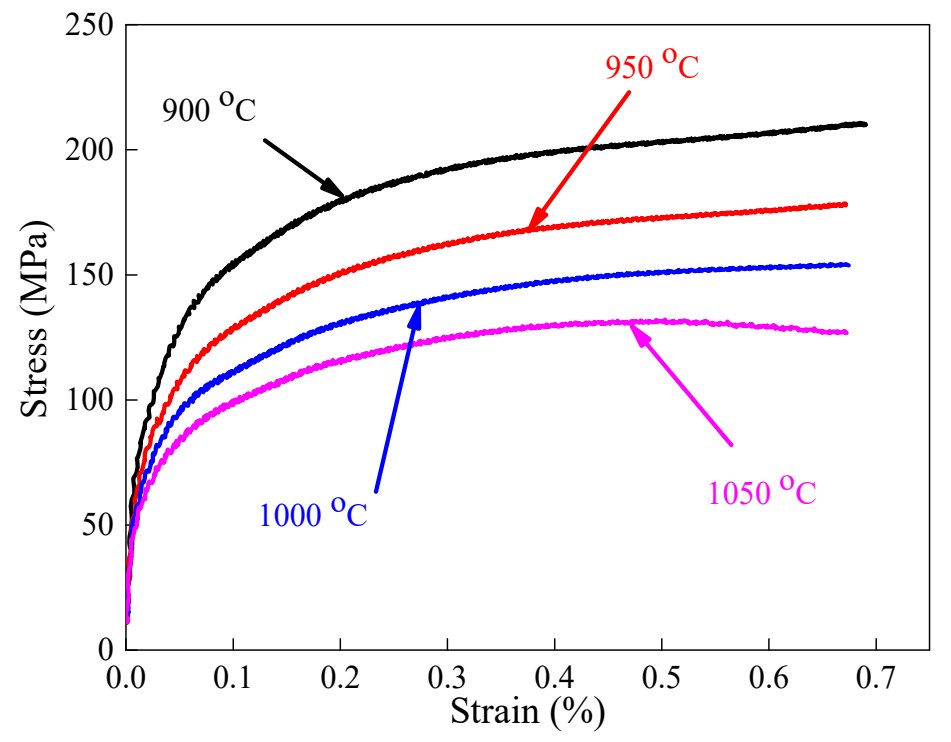

Figure 3. True stress-true strain curve with different deformation temperature.

Figure 4 is the true stress-strain curve at $950{ }^{\circ} \mathrm{C}$ and at different deformation rates. The deformation process can be divided into three stages. Stage I: Stress increases rapidly with the increase of the strain, which mainly leads to work hardening. Stage II: The rate of increase of stress slows down with the increase of deformation. As deformation increases to a certain extent, dynamic softening occurs (dynamic recover of austenite) [24]. At this time, work hardening and dynamic softening alternately occur, which makes a large number of dislocations disappear gradually, the deformation resistance of 
austenite decreases, and the stress-strain curve tends to be flat. Stage III: After dynamic recovery of all austenite, the stress value remains basically the same with the increase of strain $[25,26]$. It is noted that when the deformation is $\sim 20 \%$, the stress growth rate decreases gradually, which indicates that there are two processes of work hardening and dynamic softening (Stage II). When deformation is 60\%, the curve is smooth and dynamic recrystallization of austenite has taken place, reaching the dynamic equilibrium (Stage III). So, we selected these two parameters for comparison.

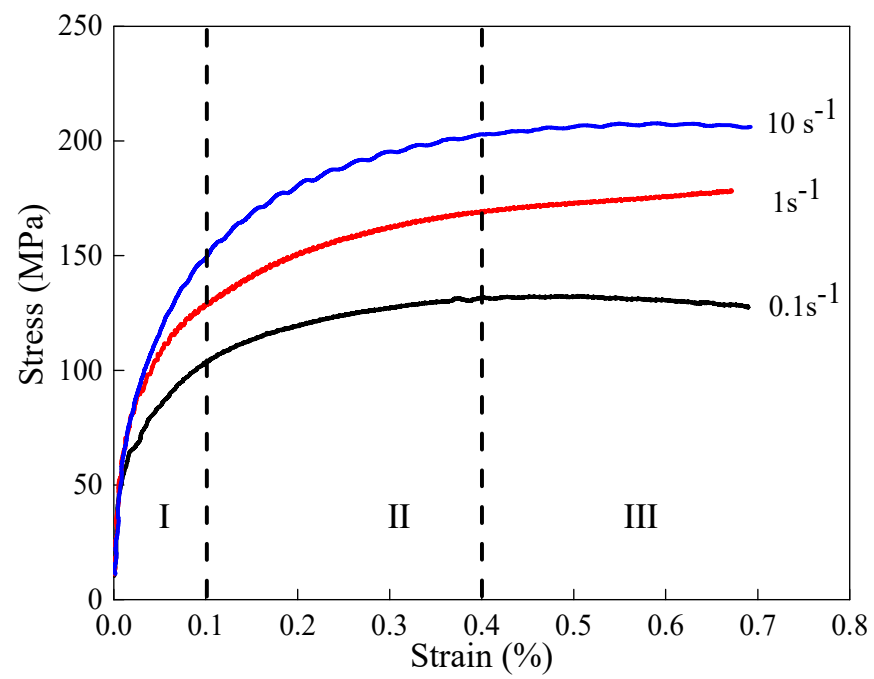

Figure 4. True stress-strain curves for different deformation rates at $950{ }^{\circ} \mathrm{C}$.

\subsection{Mechanical Properties}

Figure 5a shows tensile properties of 20Mn2SiCrNi steel with a degree of deformation of $20 \%$ and $60 \%$. Tensile strength, yield strength and elongation are $1345 \mathrm{MPa}, 1138 \mathrm{MPa}$ and $15 \%$ when the deformation is $20 \%$. They are $1432 \mathrm{MPa}, 1188 \mathrm{MPa}$ and $17.5 \%$ when the deformation is $60 \%$. The tensile strength and yield strength increased by $6.5 \%$ and $4.4 \%$, respectively, compared with the $20 \%$ deformation. The impact toughness at room temperature $\left(25^{\circ} \mathrm{C}\right)$ and low temperature $\left(-40^{\circ} \mathrm{C}\right)$ corresponding to different degrees of deformation is shown in Figure $6 \mathrm{~b}$. It increases from $115 \mathrm{~J} / \mathrm{cm}^{2}$ to $210 \mathrm{~J} / \mathrm{cm}^{2}$ at $25{ }^{\circ} \mathrm{C}$ and from $63 \mathrm{~J} / \mathrm{cm}^{2}$ to $142 \mathrm{~J} / \mathrm{cm}^{2}$ at $-40^{\circ} \mathrm{C}$. It is concluded that a main reason for the improvement of the room temperature toughness and low temperature toughness is the increase of the degree of deformation. It shows that increasing the degree of deformation not only improves toughness but also strength and elongation of 20Mn2SiCrNi steel.
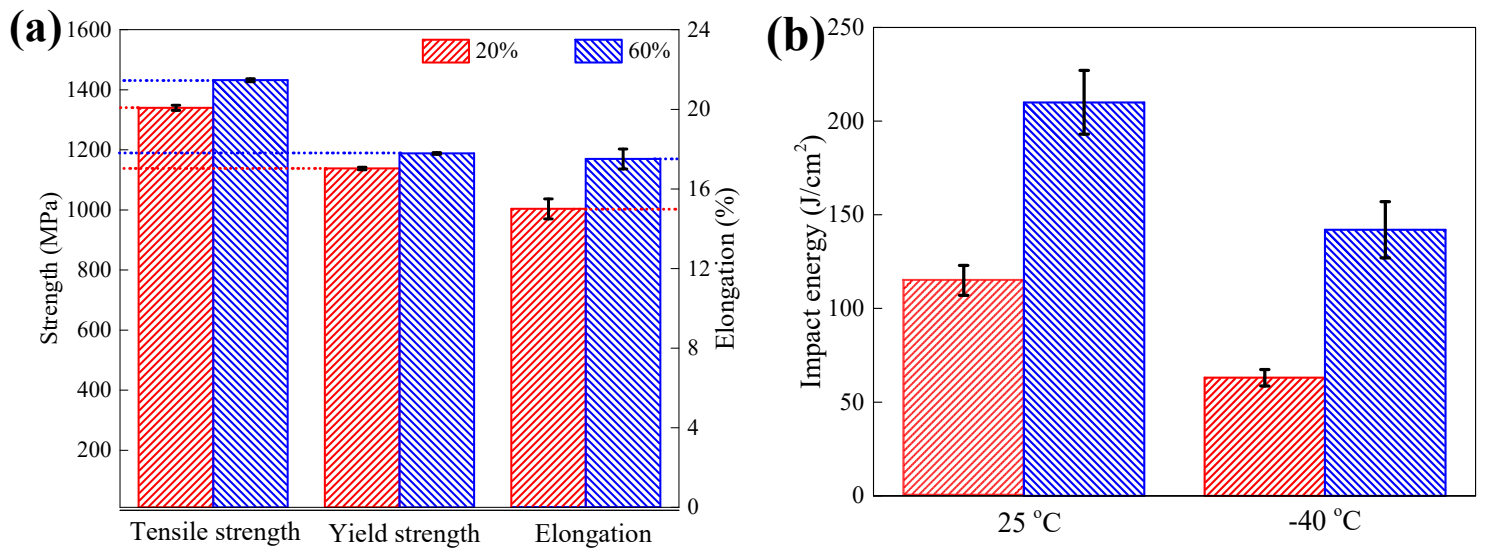

Figure 5. Change in (a) the value of tensile strength, yield strength and elongation at $25^{\circ} \mathrm{C}$ and (b) impact toughness of the $20 \mathrm{Mn} 2 \mathrm{SiCrNi}$ hot-rolled plate specimens with different degrees of deformation. 
It can be seen that the fracture was ductile (Figure $6 a, b)$. The smooth region of the steel with $20 \%$ deformation is smaller than at $60 \%$ deformation, while its crystallization region is larger, which means that $60 \%$ deformation consumes more energy during the fracture process. In order to further understand the crack propagation process during impact, the microstructure of the smooth zone is observed along the middle line of the fracture (Figure $6 c, d$ ). The single crack propagation path of $20 \%$ deformation is larger than $60 \%$ deformation. The crack deflection with $20 \%$ deformation is smooth, and the $60 \%$ deformation is more tortuous. The grain refinement leads to the microstructure refinement, which brings more obstacles to the crack growth. Irregular surface along the fracture direction in crystallization region is also observed in the matrix structure with $60 \%$ deformation. For all these characteristics, it indicates higher toughness for $60 \%$ deformation.
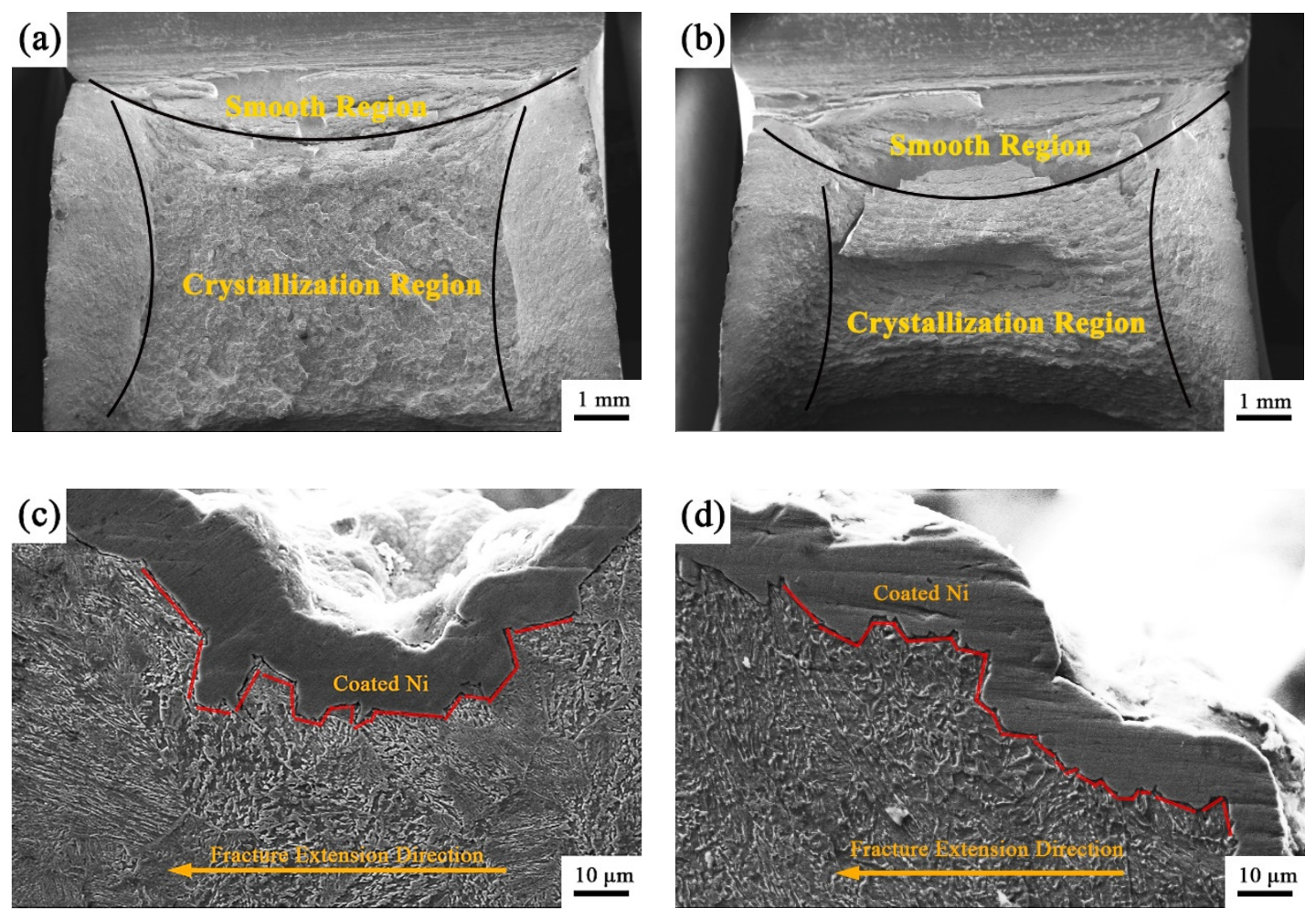

Figure 6. Fracture morphology of $20 \mathrm{Mn} 2 \mathrm{SiCrNi}$ steel: (a) impact fracture macro morphologies of $20 \%$ deformation; (b) impact fracture macro morphologies of $60 \%$ deformation; (c) microstructure of the fibrous zone along the side of the fracture of $20 \%$ deformation; (d) microstructure of the fibrous zone along the side of the fracture of $60 \%$ deformation.

\subsection{Microstructure}

Figure 7 shows the grain size for $20 \%$ and $60 \%$ deformation. When the degree of deformation is $20 \%$, prior austenite grain size is $32 \pm 2.5 \mu \mathrm{m}$. When the degree of deformation is $60 \%$, grain size of the prior austenite is $14.5 \pm 1.6 \mu \mathrm{m}$. The smaller deformation does not provide a good refinement effect. The grain of $60 \%$ deformation is mostly fine with equiaxed grain structure. Meanwhile, it has been studied that some dislocations generated with the larger deformation will disappear or rearrange by slip or climb when the deformation temperature is high, which means that the dynamic recovery of austenite will occur [27]. The stored energy of the larger deformation inside the material will increase continuously. Under high energy impact, austenite nucleation may occur at potential nucleation sites such as grain boundaries, dislocations and vacancies (dynamic recrystallization of austenite) [28,29]. 

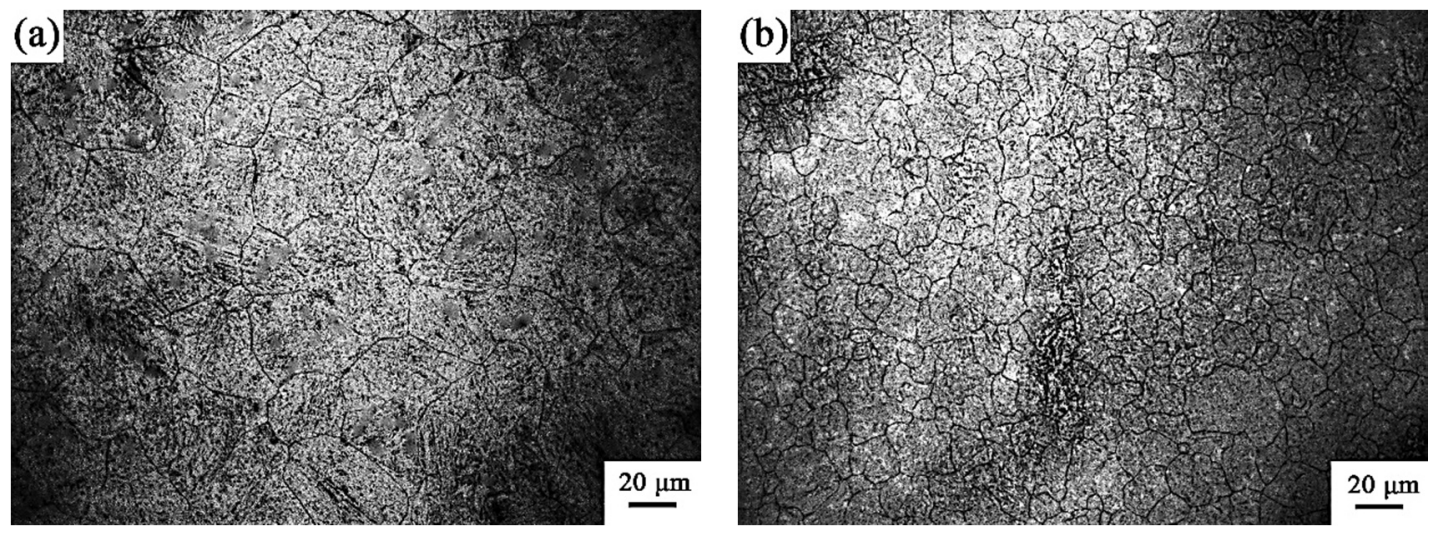

Figure 7. Grain size with different degrees of deformation: (a) 20\%; (b) $60 \%$.

Figure 8 shows the SEM micrographs with different degrees of deformation. Figure $8 \mathrm{a}, \mathrm{c}$ are the microstructure with $20 \%$ deformation. Figure $8 \mathrm{~b}$,d are microstructures with $60 \%$ deformation. Comparing Figure $8 \mathrm{a}, \mathrm{b}$, it may be noted that the microstructures corresponding to different degrees of deformation are similarly composed of granular bainite (GB), a small amount of lath bainite (LB) and martensite/austenite (MA) islands. Increasing degrees of deformation can refine the grains. From Figure $8 \mathrm{c}, \mathrm{d}$, it can be clearly seen that higher deformation refines the size of MA islands.
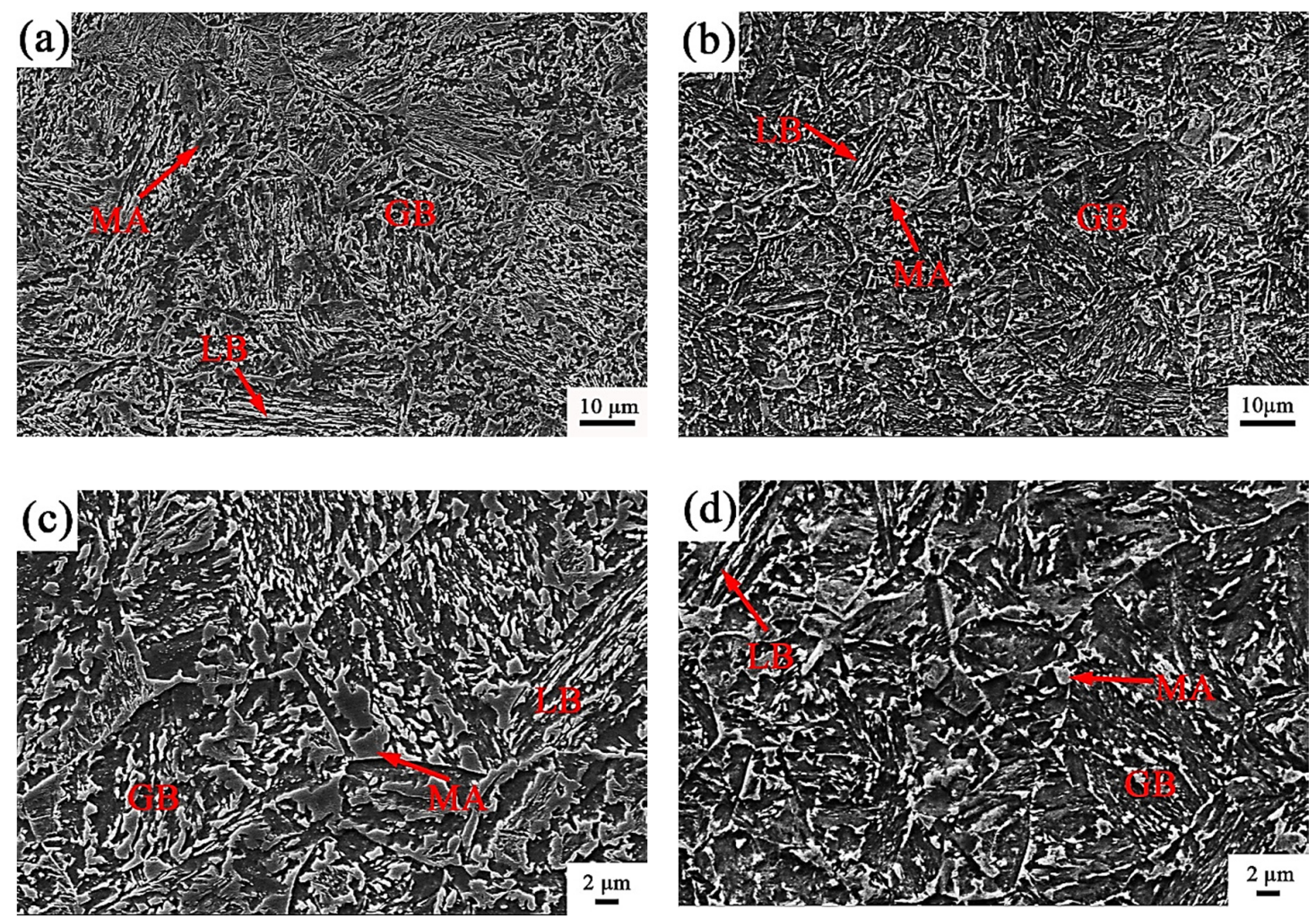

Figure 8. SEM micrographs with $20 \%$ and $60 \%$ deformation: (a) and (c), SEM of $20 \%$ deformation; (b) and (d), SEM of $60 \%$ deformation. GB: granular bainite, LB: lath bainite, MA: martensite/austenite islands.

\subsection{Effect of Deformation on Retained Austenite}

The retained austenite (RA) content is determined by XRD (Figure 9). When the degree of deformation is $20 \%$, the volume fraction of RA is $9.4 \% \pm 0.28$, and when the degree of deformation is $60 \%$, it was $9.2 \% \pm 0.15$. The volume fraction of RA for the two degrees of deformation is not basically different. EBSD is used to characterize the distribution of retained austenite (RA), (Figure 10). However, 
blocky-type retained austenite is observed when the degree of deformation is $20 \%$, while retained austenite is obviously refined when the degree of deformation is $60 \%$. The decrease of blocky-type retained austenite and increase of filmy retained austenite are conducive to the improvement of toughness [5]. The TEM images of $20 \%$ and $60 \%$ deformation samples (Figure 11a,b) verify the existence of filmy retained austenite with micrometers length between bainite lath. Some structures (such as lath bainite bundles) are refined. At the same time, there is a small amount of $\varepsilon$-carbide precipitation in the matrix and some of that may lead to tipping stress concentration.

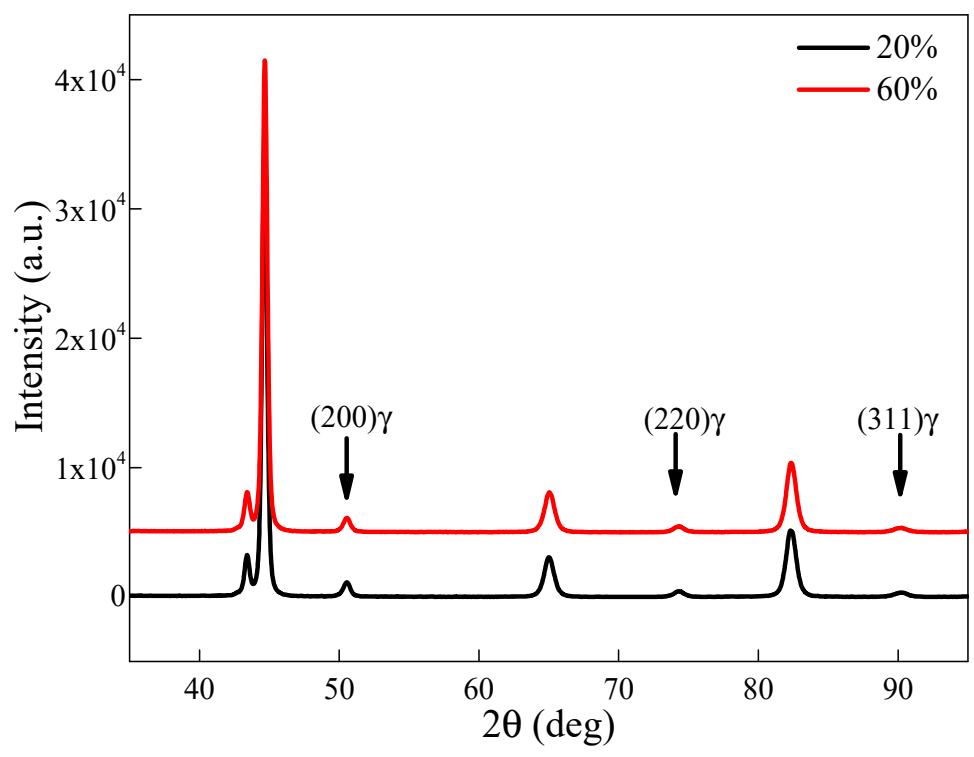

Figure 9. X-ray diffraction pattern with different degrees of deformation.
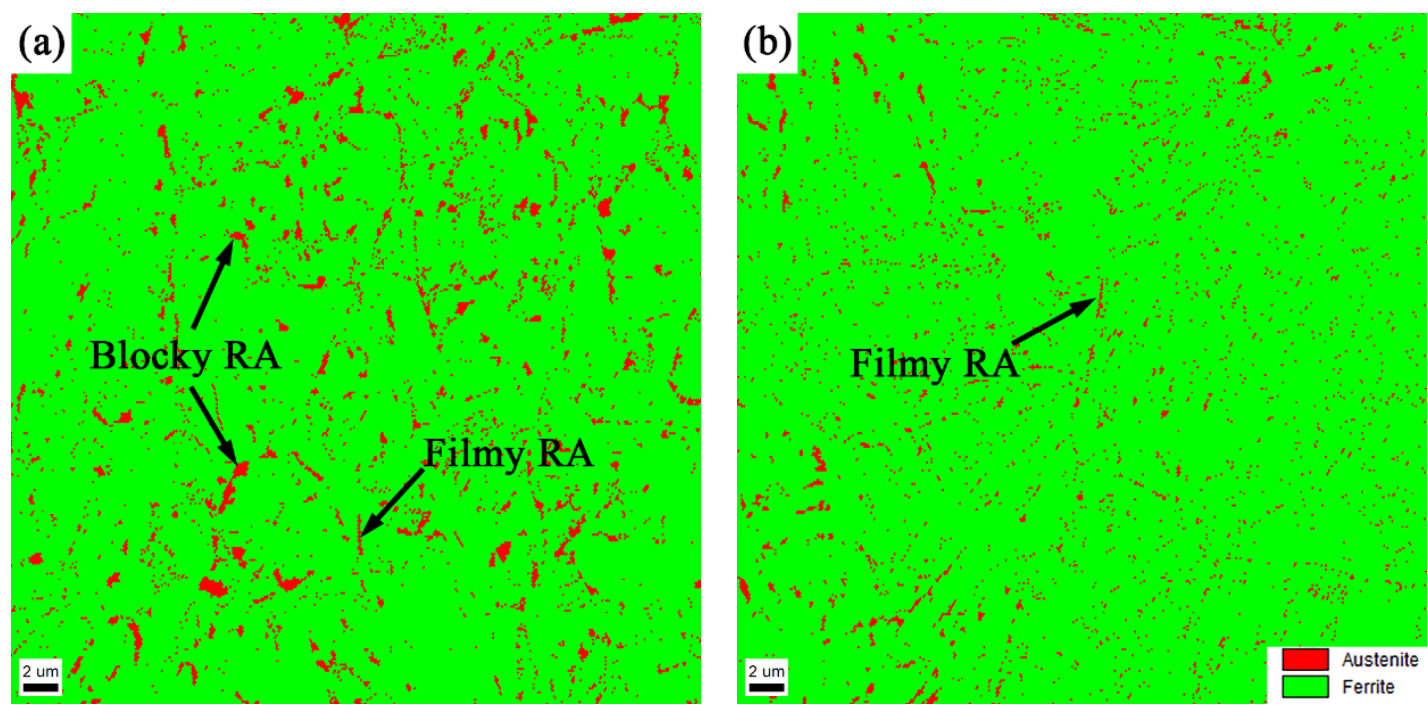

Figure 10. EBSD analysis for retained austenite distribution: (a) 20\%; (b) 60\%. 

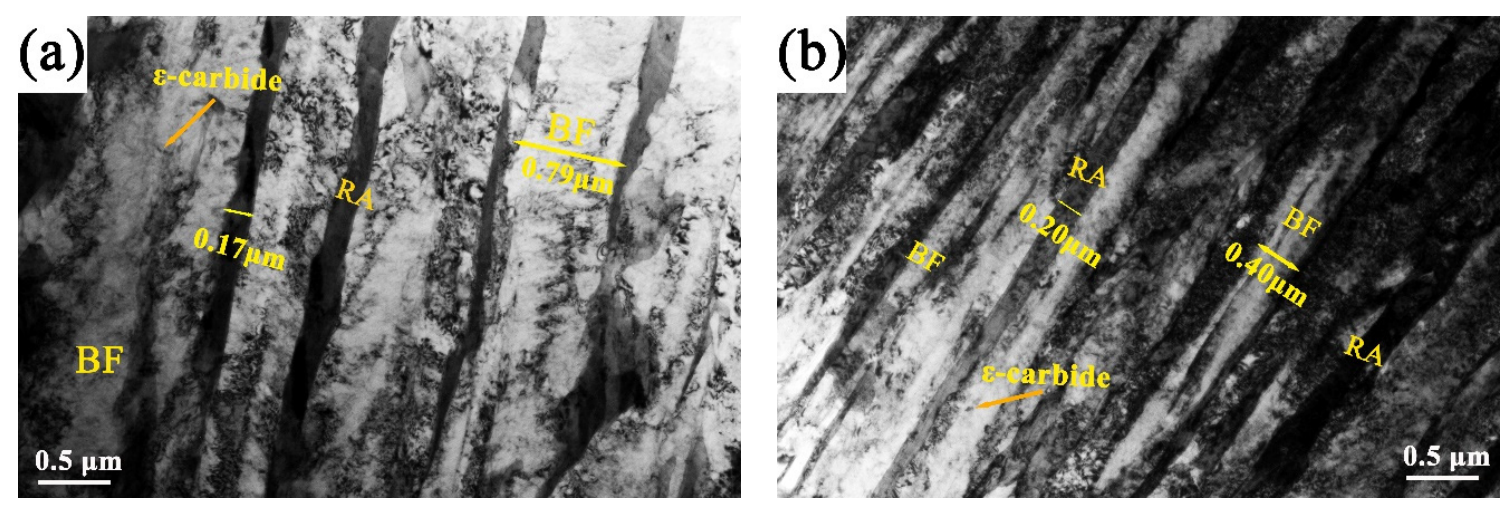

Figure 11. TEM micrographs with $20 \%$ and $60 \%$ deformation: (a) $20 \%$; (b) $60 \%$.

\subsection{Discussion of Toughening Effect}

EBSD is used to characterize the micro-orientation with 20\% and 60\% deformation (Figure 12). Grains boundaries with different angles are shown in Figures 12 and 13. According to the corresponding orientation map, a grain is divided into many blocks in which the size is refined from $\sim 5$ microns to $\sim 2$ microns as shown in Figures 12b and 13b. It is obvious when the degree of deformation is $60 \%$ based on the various color of grains. As the amount of deformation increases, the portion of high-angle grain boundaries increases from $46.7 \%$ to $52.9 \%$, reflected in the distribution of boundary misorientation, and it is conducive to the improvement of toughness [5].

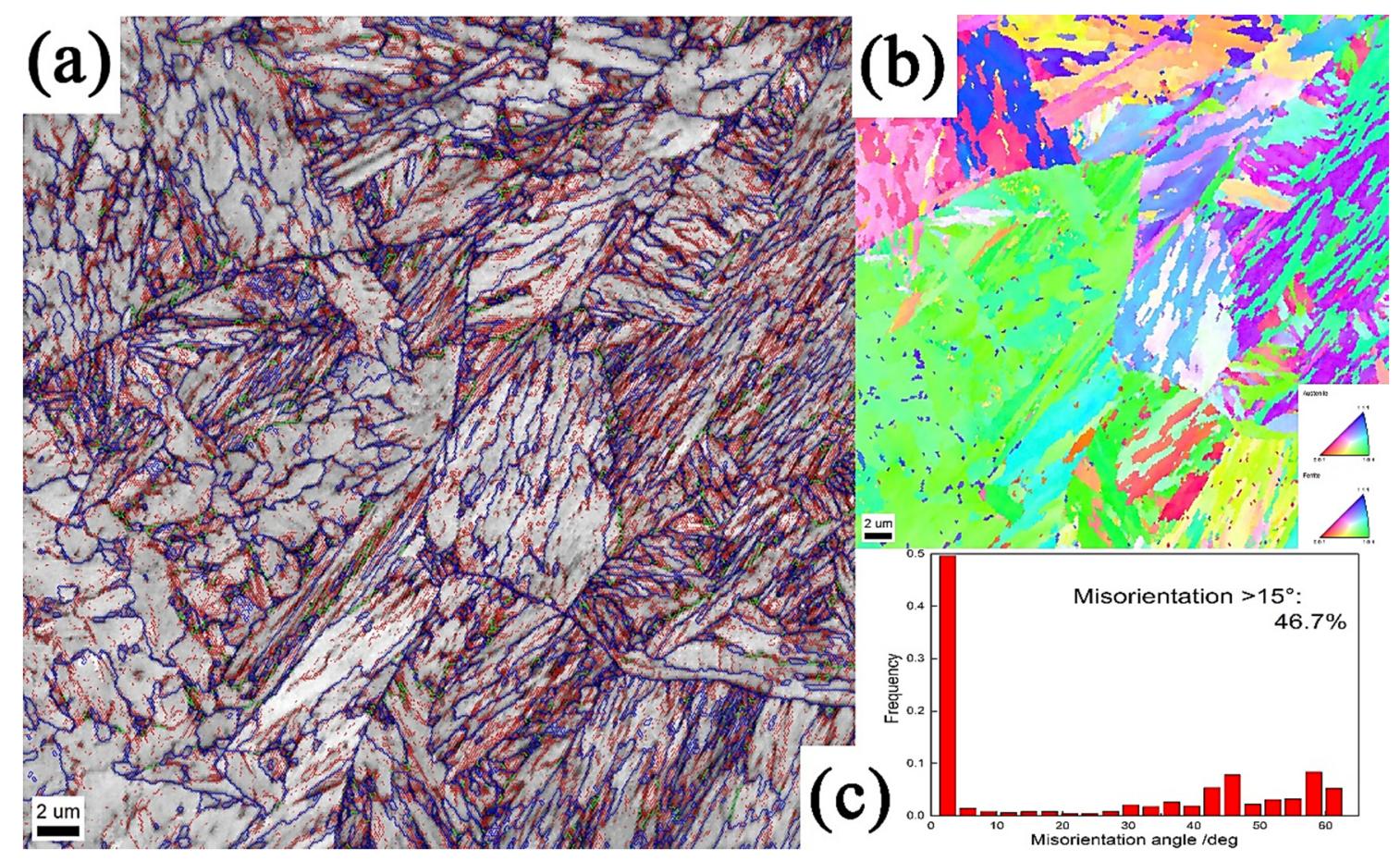

Figure 12. EBSD results of the sample with $20 \%$ deformation: (a) contrast micrograph (the red lines are low-angle boundaries with misorientation angles between $2^{\circ}$ and $15^{\circ}$ while the blue lines are high-angle boundaries with misorientation angles over $15^{\circ}$ ); (b) corresponding orientation map; (c) distribution of boundary misorientation. 


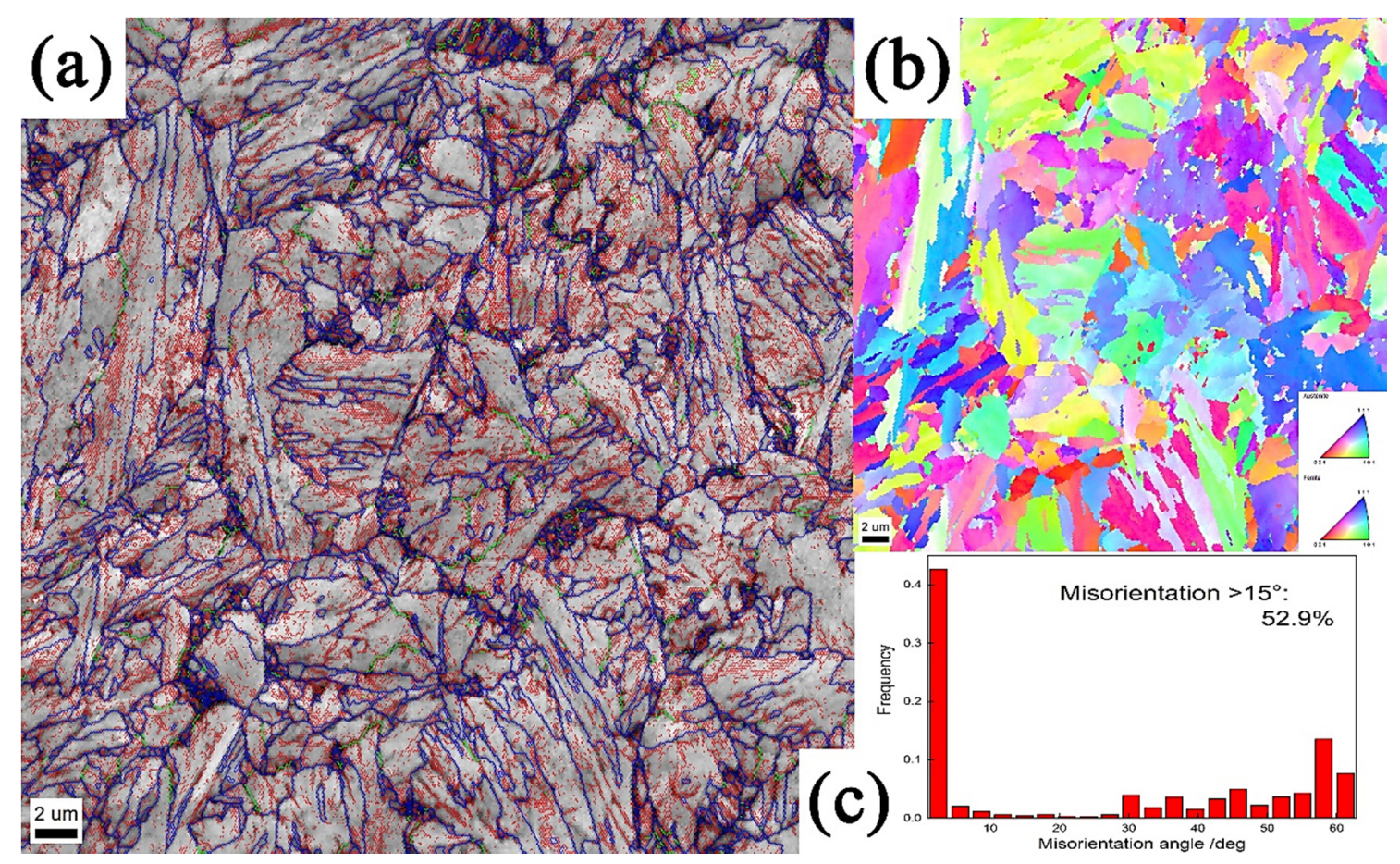

Figure 13. EBSD results of the sample with $60 \%$ deformation: (a) contrast micrograph (the red lines are low-angle boundaries with misorientation angles between $2^{\circ}$ and $15^{\circ}$ while the blue lines are high-angle boundaries with misorientation angles over $15^{\circ}$ ); (b) corresponding orientation map; (c) distribution of boundary misorientation.

Therefore, a reasonable model can be obtained based on the deformation results and microstructure analysis (Figure 14). After small (20\%) deformation, both blocky and filmy austenite were generated in microstructure, which are represented by red pentagons and ovals, respectively. The bainite lath, represented by blue rectangles, is wider compared to $60 \%$ deformation. Meanwhile, a decreased grain size was generated, refined bainite lath and filmy RA, when the deformation was $60 \%$. The amount of RA is basically the same while after $60 \%$, thin filmy RA is obtained. When increasing the amount of deformation, more nucleation positions were provided for bainite growth due to the function of refining grains. Obviously, the smaller sizes of blocky austenite were found, which is helpful to hinder the crack propagation.

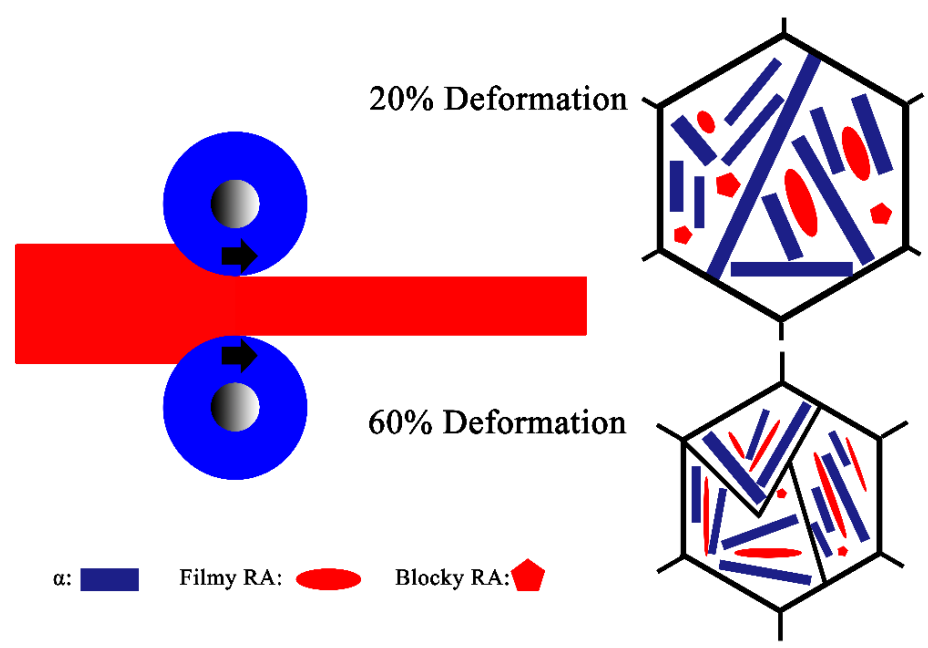

Figure 14. Model of microstructure morphology based on $20 \%$ and $60 \%$ deformation. 


\section{Conclusions}

(1) The thermal simulation experiment suggested that the deformation temperature was the key parameter during the hot deformation process. Grain size and deformation resistance should be taken into account in the selection of the deformation temperature in 20Mn2SiCrNi bainitic high strength steel.

(2) The toughness of $20 \mathrm{Mn} 2 \mathrm{SiCrNi}$ bainitic high strength steel was significantly enhanced through the increase of degree of deformation during the hot rolling process.

(3) In Mn-Si-Cr bainitic high strength steel, increasing the deformation during rolling refines grain size and microstructure, which is an effective way to improve the mechanical properties.

Author Contributions: Conceptualization, Z.T. and B.B.; methodology, Y.T.; validation, J.L., M.Z. and B.B.; formal analysis, Y.T.; investigation, J.L.; resources, M.Z.; data writing-original draft preparation, Y.T.; writing-review and editing, Y.T.; visualization, Y.T.; supervision, B.G.; funding acquisition, Z.T. All authors have read and agreed to the published version of the manuscript.

Funding: This research was funded by the Fundamental Research Funds for the Central Universities, grant number 2019JBM103.

Conflicts of Interest: The authors declare no conflict of interest.

\section{References}

1. Patel, V.K.; Bhole, S.D.; Chen, D.L. Ultrasonic spot welding of aluminum to high-strength low-alloy steel: Microstructure, tensile and fatigue properties. Metall. Mater. Trans. A 2014, 45, 2055-2066. [CrossRef]

2. Chen, X.; Huang, Y. Hot deformation behavior of HSLA steel Q690 and phase transformation during compression. J. Alloys Compd. 2015, 619, 564-571. [CrossRef]

3. Chen, X.; Huang, Y.; Lei, Y. Microstructure and properties of $700 \mathrm{MPa}$ grade HSLA steel during high temperature deformation. J. Alloys Compd. 2015, 631, 225-231. [CrossRef]

4. Luo, K.; Bai, B. Microstructure, mechanical properties and high stress abrasive wear behavior of air-cooled Mn-Cr-B cast steels. Mater. Des. 2010, 31, 2510-2516. [CrossRef]

5. Gao, G.; Zhang, H.; Gui, X.; Luo, P.; Tan, Z.; Bai, B. Enhanced ductility and toughness in an ultrahigh-strength Mn-Si-Cr-C steel: The great potential of ultrafine filmy retained austenite. Acta Mater. 2014, 76, 425-433. [CrossRef]

6. Feng, C.; Fang, H.S.; Bai, B.Z. Microstructure and mechanical properties of F_(GBA)/B_G air cooling bainitic steels containing niobium. Int. J. Miner. Metall. Mater. 2010, 17, 429-434. [CrossRef]

7. Tan, Z.; An, B.; Gao, G.; Gui, X.; Bai, B.; Tan, Z.; An, B.; Gao, G.; Gui, X.; Bai, B. Analysis of softening zone on the surface of 20Mn2SiCrMo Bainitic railway switch. Eng. Fail. Anal. 2015, 47, 111-116. [CrossRef]

8. Wang, K.; Tan, Z.; Gao, G.; Gui, X.; Misra, R.D.; Bai, B. Ultrahigh strength-toughness combination in Bainitic rail steel: The determining role of austenite stability during tempering. Mater. Sci. Eng. A 2016, 662, 162-168. [CrossRef]

9. Shen, X.J.; Tang, S.; Chen, J.; Liu, Z.Y.; Misra, R.D.K.; Wang, G.D. Grain refinement in surface layers through deformation-induced ferrite transformation in microalloyed steel plate. Mater. Des. 2017, 113, 137-141. [CrossRef]

10. Fernández, J.; Illescas, S.; Guilemany, J.M. Effect of microalloying elements on the austenitic grain growth in a low carbon HSLA steel. Mater. Lett. 2007, 61, 2389-2392. [CrossRef]

11. Kennett, S.C.; Krauss, G.; Findley, K.O. Prior austenite grain size and tempering effects on the dislocation density of low-C Nb-Ti microalloyed lath martensite. Scr. Mater. 2015, 107, 123-126. [CrossRef]

12. Liu, B.X.; Wei, J.Y.; Yang, M.X.; Yin, F.X.; Xu, K.C. Effect of heat treatment on the mechanical properties of copper clad steel plates. Vacuum 2018, 154, 250-258. [CrossRef]

13. Atanu, S.; Mondal, D.K.; Biswas, K.; Maity, J. Development of high strength ductile hypereutectoid steel by cyclic heat treatment process. Mater. Sci. Eng. A 2012, 541, 204-215.

14. Li, J.; Tan, Z.; Zhang, M.; Gao, G.; Misra, R.D.K.; Bai, B. On the significant impact of deformation coupled with cooling rate during Thermo-Mechanical Controlled Processing (TMCP) on microstructure-property relationship in 25Mn2Si2Cr high strength steel. Steel Res. Int. 2019, 90. [CrossRef] 
15. Mishra, A.; Mondal, C.; Maity, J. Microstructural modifications in AISI 1080 eutectoid steel under combined cyclic heat treatment. Steel Res. Int. 2016, 87, 424-435. [CrossRef]

16. Ji, G.; Li, L.; Qin, F.; Zhu, L.; Li, Q. Comparative study of phenomenological constitutive equations for an as-rolled M50NiL steel during hot deformation. J. Alloys Compd. 2017, 695, 2389-2399. [CrossRef]

17. Li, J.; Gao, B.; Huang, Z.; Zhou, H.; Mao, Q.; Li, Y. Design for strength-ductility synergy of 316L stainless steel with heterogeneous lamella structure through medium cold rolling and annealing. Vacuum 2018, 157, 128-135. [CrossRef]

18. Gong, P.; Palmiere, E.J.; Rainforth, W.M. Thermomechanical processing route to achieve ultrafine grains in low carbon microalloyed steels. Acta Mater. 2016, 119, 43-54. [CrossRef]

19. Wang, C.Y.; Zhang, Y.J.; Cao, W.Q.; Shi, J.; Wang, M.Q.; Dong, H. Austenite/martensite structure and corresponding ultrahigh strength and high ductility of steels processed by Q\&P techniques. Sci. Chin. Tech. Sci. 2012, 55, 1844-1851.

20. Dijk, N.H.V.; Butt, A.M.; Zhao, L.; Sietsma, J.; Offerman, S.E.; Wright, J.P.; Zwaag, S.V.D. Thermal stability of retained austenite in TRIP steels studied by synchrotron X-ray diffraction during cooling. Acta Mater. 2005, $53,5439-5447$.

21. Chi, Z.; Zhang, L.; Shen, W.; Liu, C.; Xia, Y.; Li, R. Study on constitutive modeling and processing maps for hot deformation of medium carbon Cr-Ni-Mo alloyed steel. Mater. Des. 2015, 90, 804-814.

22. Han, Y.; Shi, J.; Xu, L.; Cao, W.Q.; Dong, H. Effect of hot rolling temperature on grain size and precipitation hardening in a Ti-microalloyed low-carbon martensitic steel. Mater. Sci. Eng. A 2012, 553, 192-199. [CrossRef]

23. Sung, H.K.; Sohn, S.S.; Sang, Y.S.; Lee, S.; Kim, N.J.; Chon, S.H.; Yoo, J.Y. Effects of finish rolling temperature on inverse fracture occurring during drop weight tear test of API X80 pipeline steels. Mater. Sci. Eng. A 2012, 541, 181-189. [CrossRef]

24. Dougherty, L.M.; Robertson, I.M.; Vetrano, J.S. Direct observation of the behavior of grain boundaries during continuous dynamic recrystallization in an Al-4Mg-0.3Sc alloy. Acta Mater. 2003, 51, 4367-4378. [CrossRef]

25. Chen, F.; Wang, H.; Zhu, H.; Cui, Z. Study on dynamic recrystallization behaviors in a hot-deformed FB2 ultra-supercritical rotor steel. Metall. Microstruct. Anal. 2019, 8, 145-158. [CrossRef]

26. Xin, D.; Bin, Y. Study on hot deformation behavior and processing maps of SA508-V steel for novel nuclear reactor pressure vessels. Vacuum 2018, 155, 637-644.

27. Ebrahimi, G.R.; Keshmiri, H.; Momeni, A.; Mazinani, M. Dynamic recrystallization behavior of a superaustenitic stainless steel containing $16 \% \mathrm{Cr}$ and 25\%Ni. Mater. Sci. Eng. A 2011, 528, 7488-7493. [CrossRef]

28. Momeni, A.; Dehghani, K.; Keshmiri, H.; Ebrahimi, G.R. Hot deformation behavior and microstructural evolution of a superaustenitic stainless steel. Mater. Sci. Eng. A 2010, 527, 1605-1611. [CrossRef]

29. Li, J.; Tan, Z.; Zhang, M.; Gao, G.; Misra, R.D.K.; Bai, B. Effect of intercritical austenitizing temperature during quenching-intercritical quenching-tempering process on toughness of 25Mn2Si2Cr bainitic steel. Steel Res. Int. 2019, 90. [CrossRef]

(C) 2019 by the authors. Licensee MDPI, Basel, Switzerland. This article is an open access article distributed under the terms and conditions of the Creative Commons Attribution (CC BY) license (http://creativecommons.org/licenses/by/4.0/). 